\title{
ВОЗМОЖНОСТИ ПРИМЕНЕНИЯ СИСТЕМЫ \\ ВИЗУАЛИЗАЦИИ IN-VIVO FX PRO (BRUCKER) ПРИ ИЗУЧЕНИИ ОСТЕОПРОТЕКТИВНОГО ДЕЙСТВИЯ ЛЕКАРСТВЕННЫХ СРЕДСТВ
}

\author{
О.С. Гудырев, М.О. Мишенин \\ ФГАОУ ВО «Белгородский государственный национальный исследовательский \\ университет».
}

DOI: 10.19163/MedChemRussia2021-2021-466

E-mail: gudyrev@bsu.edu.ru

Система молекулярной визуализации In-Vivo FX PRO производства Bruker (США) - это полностью автоматизированная система визуализации для работы с мелкими лабораторными животными. Система молекулярной визуализации In-Vivo FX PRO работает с флуоресценцией на различных длинах волн, белым светом, люминесценцией, излучением радиоизотопов и рентгеновским излучением, в том числе с возможностью одновременной регистрации объектов in-vivo в различных спектрах для улучшения локализации биомаркеров в организме лабораторного животного. При этом автоматизированная камера позволяет дистанционно переключать режимы визуализации, не тревожа объект исследования.

Система In-Vivo FX PRO может с успехом применяться в сфере доклинических исследований для изучения остеотропных свойств новых оригинальных и воспроизведенных лекарственных средств. Так, возможность работы в рентгеновском спектре позволяет в динамике оценивать развитие воспроизведенных экспериментальным путем остеопоротических, остеосклеротических или остеонекротических изменений различных костей скелета мелких лабораторных животных. Система предоставляет возможность прижизненной визуализации и оценки эффективности протекания процессов репаративной регенерации костно-травматических повреждений в динамике, в том числе на фоне применения лекарственных средств, стимулирующих остеогенез. Таким образом, становится возможной объективная оценка антиостеопоротического действия лекарственных средств или их стимулирующего влияния на регенерацию костной ткани при экспериментальных повреждениях.

Программное обеспечение для измерения плотности костной ткани использует изображения высокого пространственного разрешения, полученные с помощью низких доз рентгеновского излучения, для проведения точных измерений в определенных сегментах длинных трубчатых костей. В качестве таких костей у мелких лабораторных животных могут выступать бедренная, большеберцовая, плечевая и лучевая кости, у более крупных животных дополнительно фаланги пальцев передних и задних конечностей. Программное обеспечение для измерения плотности костной ткани позволяет оценивать: плотность костного мозга; плотность кортикальной и губчатой костной ткани; плотность поверхности кости и костного мозга; объемную плотность кости.

Таким образом, система In-Vivo FX PRO является мощным инструментом для проведения доклинических исследований лекарственных средств, в том числе в области экспериментальной остеологии.

$$
-466-
$$

